\title{
Cross-national differences in the association between educational attainment and completed fertility. Do welfare regimes matter?
}

\author{
Eva-Maria Merz and Aart C. Liefbroer*
}

\begin{abstract}
The decline in fertility has been linked to changes in educational attainment, particularly among women. Most studies on this topic have, however, focused on the impact of education on fertility timing. In this study, we examine the association between education and completed fertility; specifically, whether the educational gradient differs between women and men and between younger and older birth cohorts. Importantly, we investigate whether the educational gradient varies across European welfare systems. In our analysis, we applied multilevel modelling to individual-level data on fertility quantum in 25 countries from the European Social Survey. Overall, women and older cohorts had higher completed fertility rates than men and younger cohorts. The total number of children born to each individual decreased with increasing educational levels. This negative gradient was stronger among women than among men, and was weaker among younger than among older cohorts in western Europe. At the macro level, we found the weakest negative educational gradients in the social-democratic countries and in the post-Soviet states. The negative gradient was strongest in the Mediterranean countries and in the postcommunist countries.
\end{abstract}

\footnotetext{
* Eva-Maria Merz (corresponding author), Sanquin Research, Department of Donor Studies, Plesmanlaan 125, 1066 CX Amsterdam, The Netherlands

and

Department of Sociology, Vrije Universiteit, Amsterdam, The Netherlands Email: e.merz@Sanquin.nl

Aart C. Liefbroer, Netherlands Interdisciplinary Demographic Institute, The Hague, and Department of Epidemiology, University Medical Center Groningen, University of Groningen, and Department of Sociology, Vrije Universiteit, Amsterdam, The Netherlands
} 


\section{Introduction}

Over the last half century, the fertility patterns of Europe have changed markedly. With some variation between countries, throughout Europe the timing of entry into parenthood has been postponed, the prevalence of childlessness has increased, the total number of children in each family has decreased, and the proportion of children born outside of marriage has increased (Frejka 2008; Frejka and Sobotka 2008; Kreyenfeld 2010). Numerous theories have been put forward to explain these changes (e.g. Becker 1981; Lesthaeghe 1995; Van de Kaa 1996; McDonald 2000; Blossfeld et al. 2003; Esping-Andersen 2009; Perelli-Harris et al. 2010). What all of these theories have in common is that they suggest that educational attainment - and particularly the increase in educational attainment among women, which is linked to higher rates of female labour force participation - is a key driving force of these changes in fertility.

In tandem with the emergence of these theoretical ideas, a burgeoning empirical literature has developed that examines cross-national differences in the relationship between educational attainment or female employment on the one hand and fertility on the other. This is a very challenging research area, as researchers wishing to study this topic are faced with a number of questions. In our view, researchers have to make at least four decisions, either explicitly or implicitly. The first of these decisions pertains to the "dependent variable". It is possible to analyse either the relationship between educational attainment and specific parity progression ratios (e.g. Kreyenfeld 2010; Van Bavel 2010; Stange 2011; Wood et al. 2014), or the relationship between educational attainment and completed or total fertility (e.g. Engelhardt et al. 2004; Hilgeman and Butts 2009). The second decision concerns the type of macro-level explanation that is used. Does the explanation focus on cultural, economic, or institutional factors? While these three broad types of factors are obviously not mutually exclusive (as is made clear in, for instance, Van Bavel 2010), studies tend to focus on one of these factors more than the others. The third decision involves determining whether the macro-level explanation emphasises specific characteristics of national contexts; and, if so, whether it is preferable to test the relevance of these specific characteristics (e.g. Kalwij 2010) or to focus on a constellation of characteristics that form a kind of package (e.g. Matysiak and Vignoli 2007). The fourth and final decision involves choosing whether to classify countries on a one-dimensional or a multidimensional scale (e.g. Hilgeman and Butts 2010), or to use a typological approach in which countries are grouped based on how similar or dissimilar they are on the key dimensions of interest is preferable (e.g. Matysiak and Vignoli 2007).

Which of these approaches an individual researcher takes depends on both theoretical and practical considerations. The practical considerations are usually related to the type of data that are available. Richer data are needed when using a parity-specific approach than when using an approach that focuses on completed or total fertility only; and more specific data at the macro level are needed when employing a scaling approach than when using a typological approach. Theoretical 
considerations are important as well. For example, should the study take into account specific macro characteristics only, or a package of characteristics? What kinds of macro characteristics are considered most important? In our view, there is no single approach that is best suited to investigating cross-national differences. Rather, we contend that it is useful to stimulate the application of different types of approaches that - when viewed in conjunction with each other - can offer complementary insights.

In this article, we take a broad approach to our subject matter. We examine the association between educational attainment and completed fertility among cohorts who have (almost) finalised their reproductive careers, and study whether this association varies across Europe. In particular, we consider differences across welfare systems. We have both practical and theoretical reasons for focusing on completed fertility. Our data source (the European Social Survey) includes information on a larger number of European countries than other data sources (e.g. GGP or SHARE), but lacks full information on the timing of all childbirths. Although the information provided by a parity-specific approach is richer, our approach is simpler, and provides a relatively straightforward answer to the question of whether the relationship between educational attainment and final levels of fertility differs across countries. We also have practical and theoretical reasons for focusing on welfare systems. As the cohorts in our dataset were born between 1905 and 1966, we lack indicators of specific welfare arrangements during the childbearing ages of a large share of these cohorts. It is, however, possible to use a more global approach to the categorisation of welfare systems. Theoretically, it could be argued that the package of institutional arrangements matters more than the specific arrangements. If this is the case, it makes sense to use a broad welfare state typology to test whether the relationship between educational attainment and completed fertility differs across countries. A final defining feature of our approach is that we examine the educational gradient in completed fertility not only among women, but also among men. To empirically test our hypotheses, we have applied multi-level modelling to individual-level data on fertility quantum collected in 25 countries in the 2006 wave of the European Social Survey.

\section{Background and hypotheses}

In this section, we discuss the literature on the differences in the educational gradient of completed fertility across welfare systems, and develop hypotheses regarding these differences. First, however, we provide a brief overview of the main arguments that have been made in the debate over the relationship between educational attainment and completed fertility.

\subsection{Educational attainment and completed fertility}

A number of arguments regarding the link between educational attainment and the total number of children have been put forward. First, with reference to the 
Second Demographic Transition (SDT) framework (Lesthaeghe and Van de Kaa 1986; Van de Kaa 1987; Lesthaeghe 1995), several scholars have argued that men and women with high levels of education tend to value autonomy more than their counterparts with low levels of education. This tendency has been attributed in part to the emphasis placed on values of self-reliance and autonomy in the curricula of higher education institutions (Meyer 1986). It has thus been posited that the highly educated have learned that they should not take existing lifestyles for granted, but should instead critically reflect upon these lifestyles (Giddens 1991). It has also been pointed out that highly educated individuals often spend considerable amounts of time away from the parental home, which may strengthen their desire for autonomy (Waite et al. 1986). This autonomy argument therefore suggests that through the experience of becoming educated, men and women come to place less value on traditional family life, which in turn leads them to choose to have no children or fewer children. The autonomy argument may apply to the younger cohorts in particular. According to the SDT theory, the processes of emancipation that have taken place in recent decades have led to a growing emphasis on individual autonomy and independence. These trends appear to be particularly salient among younger individuals.

A second, related argument is that highly educated people spend more time on childrearing than less educated individuals (Sayer et al. 2004; Craig 2006). This line of reasoning reinforces the assumptions of the classic literature on the quality/quantity trade-off; i.e. the idea that parents can choose to invest in either the number or the quality of their children (Hanushek 1992). While the focus has shifted over time from quantity to quality across the population, it is still generally the case that highly educated people are more likely to opt for quality, whereas less educated people are more likely to opt for quantity. This quality argument suggests that highly educated individuals will be more likely to have a small number of children than individuals with relatively low levels of education.

A third argument is based on the New Home Economics approach championed by Becker (1981). This incompatibility argument suggests that individuals have problems combining family and career because of time incompatibility. Growing numbers of individuals, and especially women, are admitting that parenthood limits their educational ambitions and employment opportunities (Koropeckyj-Cox and Pendell 2007). As a result of a perceived conflict between the roles associated with motherhood and professional life, highly educated women with good career opportunities may be more reluctant to have children. The picture for men is less clear, as the opportunity costs associated with parenthood are often lower for men than for women, and men's educational ambitions may not be threatened by fatherhood, especially in countries that support a male breadwinner model (Kalmijn and Saraceno 2008). Overall, the incompatibility argument suggests that highly educated individuals in particular are likely to find it difficult to reconcile work and parenthood, which may lead them to have fewer children than less educated individuals. However, this pattern might be gender-specific. 
The fourth argument, which is also based on insights from economics (Becker 1981), emphasises monetary rather than time restrictions. The affordability argument is derived from the observation that raising children is costly, and that high-income couples are better able to afford to have children than couples with lower incomes. As income is strongly linked to educational attainment, it is assumed that an increase in educational levels will lead to an increase in the number of children individuals or couples can afford to have.

Thus, three out of four of these arguments suggest that highly educated individuals will have fewer children than less educated individuals. Although this does not necessarily imply that the educational gradient will be negative, we expect to find that the affordability argument is weaker than the combined impact of the other three arguments. Thus, we hypothesise that there is a general negative association between education and completed family size. However, we also expect to find that this effect operates differently for men than for women. Specifically, we anticipate that the incompatibility argument is more relevant for women than for men, as women are often expected to take on the main responsibilities for household labour. We therefore hypothesise that the negative relationship between education and the number of children is stronger for women than for men (Hilgeman and Butts 2009; McDonald 2000). Our first two hypotheses may be summed up as follows:

H1: The completed family size of both men and women in Europe is negatively related to their level of educational attainment.

$\mathrm{H} 2$ : This negative relationship is stronger for women than for men.

\subsection{Cross-national differences in the educational gradient}

In recent years, much research has been conducted on cross-national differences in the extent to which states help women combine parenthood and paid employment. Some of that research (cf., Kalwij 2010; Adsera 2011) has been conducted at the macro level, and suggests that fertility may be higher in countries where this combination is facilitated by institutional arrangements (Engelhardt et al. 2004; Myrskylä et al. 2009; Thevenon and Gauthier 2011; Luci-Greulich and Thevenon 2013). Differences between welfare regimes may also have implications for the educational gradient in completed fertility.

Starting with the work of Esping-Andersen (1990, 1996), (European) countries have been clustered into one of a small set of welfare regimes based on how they organise the interplay between income transfers and social services. However, welfare regimes are characterised not only by the rights they grant, but by how these state activities interact with the family and the market in the provision of welfare (Esping-Andersen 1990, 1996). Esping-Andersen distinguished between liberal, social-democratic, and conservative-corporatist regimes. The liberal type which is most common in countries with an Anglo-Saxon tradition - operates on the assumption that a majority of citizens can obtain adequate welfare benefits from the market, and that the government should play only a small role in welfare 
redistribution. The conservative-corporatist welfare regime type is characterised by a moderate level of decommodification, whereby status differentials are preserved and rights are attached to class and status (Esping-Andersen 1990). The direct influence of the state is limited to providing income maintenance benefits related to occupational status (Fenger 2007). These corporatist regimes are also frequently shaped by Christian traditions (Esping-Andersen 1996). As many of the countries with a conservative-corporatist welfare regime type have been heavily influenced by the traditional family values advocated by Christian churches, the family benefits provided in these countries tend to encourage parenthood within a traditional male breadwinner model. France, Germany, Austria, Belgium, the Netherlands, and Italy are often classified as conservative-corporatist regimes. ${ }^{1}$ The third cluster, the socialdemocratic regime type, is mainly characterised by an emphasis on equalising the living conditions of the country's citizens, independent of individual contributions. This system focuses on synchronising social and labour market policies to provide citizens with relatively equal levels of income, health care access, and social benefits (Andersson et al. 2009). The Nordic countries of Denmark, Norway, Sweden, and Finland are usually classified as social-democratic regimes.

Soon after Esping-Andersen introduced his three regime types, a discussion started about whether these categories were sufficiently comprehensive; and about whether the southern European countries had been correctly classified as belonging to the conservative-corporatist regime category, or whether they should be assigned to a separate Mediterranean regime category (e.g. Ferrera 1996; Bonoli 1997). It has been suggested that Mediterranean countries deviate from the corporatist type in several ways: i.e. they have a fragmented income maintenance system, a low degree of state penetration of the welfare sphere, and a rather selective distribution of social benefits (Ferrera 1996). Thus, the Mediterranean welfare regime type is characterised by a strong reliance on the family, traditional gender role patterns, and low levels of institutionalised child care.

In central and eastern European countries, birth rates have been low since the communist system collapsed and was replaced by a capitalist market economy

\footnotetext{
1 We acknowledge that a considerable degree of heterogeneity may exist within this cluster of countries, especially with regard to the timing of the introduction of policies and infrastructures that facilitate the reconciliation of labour force participation and childrearing. France and Belgium, for example, introduced reconciliation policies - such as policies that provide access to affordable day care arrangements - much earlier than the other countries. In the current study, however, we decided to retain the original theoretically grounded classification of Esping-Andersen. Changes to this classification were only introduced based on successive theoretical discussions of welfare states. In response to the general criticism of Esping-Andersen's classification by Ferrera (1996) and Bonoli (1997), Italy was grouped with other Mediterranean countries. At the same time, we decided to keep France and Belgium in the conservative-corporatist category, as this is generally done when grouping welfare states based on general policy. However, we admit that with regard to specific reconciliation policies, France and Belgium might be closer to the Nordic welfare states than to the other conservative states. Therefore, we tested the robustness of our classification in the results section, and commented on the results in the discussion section.
} 
Table 1:

Classification of welfare states across Europe

\begin{tabular}{ll}
\hline Welfare state regimes & Countries \\
\hline Conservative-corporatist & Belgium, France, Netherlands, \\
& Austria, Germany, Switzerland \\
Social-democratic & Denmark, Finland, Norway, Sweden \\
Liberal & Great Britain, Ireland \\
Post-Soviet & Estonia, Latvia, Russia, Ukraine \\
Post-communist European & Bulgaria, Hungary, Poland, Romania, \\
& Slovenia, Slovakia \\
Mediterranean & Cyprus, Spain, Portugal \\
\hline
\end{tabular}

(Sobotka 2004). Economic restructuring and the accompanying uncertainties have led to societal transformations in these former socialist countries, which have increased the costs of childbearing (Philipov et al. 2006). The issue of how the postSoviet states and the post-communist central European countries fit into the welfare regime typology has not been fully resolved. Esping-Andersen (1996) criticised the expansion of his typology, suggesting that the differences observed between the characteristics of his welfare regime types and those of eastern European countries were transitional in nature. However, many of these differences have yet to disappear. Fenger (2007) has therefore suggested that the eastern European postcommunist countries should be assigned to one of two clusters: the post-Soviet states and the other post-communist countries. These two sets of eastern European countries have developed differently since the collapse of communism. Whereas countries like Poland and Slovenia joined the European Union after engaging in extensive negotiations and reforms, many post-Soviet states like Ukraine came under the influence of the Russian Federation. Both the post-communist eastern European and the post-Soviet welfare regimes resemble the conservative-corporatist regime type to some extent, albeit mixed with several characteristics of the socialdemocratic regime type. However, compared to the post-Soviet states, the postcommunist countries have more developed governmental programs and social services, and a more generous welfare state overall (Fenger 2007). Table 1 displays the classification of the ESS countries into these welfare regime types.

Our broad welfare state typology only allows for a general classification of countries based on how they help families combine parenthood, education, and paid employment. At the same time, the generality of this approach allows us to classify all countries, which is useful given the lack of specific policy information for several countries. In addition, we believe that this classification approach offers valuable insights into how the educational gradient in completed fertility differs across Europe. For instance, Andersson et al. (2009) pointed out that the Nordic 
social-democratic countries have similarly high levels of levels of fertility and female labour force participation, and thus have "a common Nordic fertility regime" (p. 313). In an analysis of two cohorts of Polish women, Brzozowska (2014) found large and persistent differences in fertility by educational level both before and after the collapse of communism. In the liberal countries, and especially in the UK, large educational gradients in fertility have been found (Berrington et al. 2015).

Based on these earlier studies, and taking the characteristics of different welfare regimes into account, we expect to find that parenthood and labour force participation are more compatible in the social-democratic welfare regimes and albeit to a lesser extent - in the liberal and the conservative welfare regimes than in the Mediterranean, the post-communist eastern European, and the post-Soviet welfare regimes; and that the educational gradients are therefore smaller in the first than in the second group of regimes. For instance, we expect to find that the provision of both public and private parental leave and childcare services is greater in the former than in the latter group (Hilgeman and Butts 2009). We thus formulate the following hypothesis:

H3: The negative educational gradient in completed family size is stronger in welfare regime types with poor arrangements for combining parenthood and employment than in welfare regime types with better arrangements for combining parenthood and employment.

As policies that facilitate the reconciliation of family and work have been implemented only relatively recently, we can expect to find that the negative gradient is weaker among younger cohorts (who may have benefited from these policies) than among older cohorts (who were unable to benefit from these policies). However, this cohort shift will have occurred only in welfare regimes in which these policies have improved over time. In welfare regimes in which there has been little or no improvement in these policies, no such shift across cohorts is expected. We therefore compare two cohorts - those cohorts born before 1945 and those born after 1944 and formulate the following hypothesis:

H4: The educational gradient in completed family size is weaker for younger than for older cohorts, but only in welfare regimes with policies aimed at facilitating the reconciliation of family and work.

\section{Method}

\subsection{Procedure and participants}

The data used in this study stem from the third round of the European Social Survey (ESS), which was conducted in 2005 and 2006. The ESS is a repeated cross-sectional survey that focuses on identifying cross-national differences in social attitudes and values, and on collecting high-quality data by ensuring high 
response rates (Stoop et al. 2010) and questionnaire equivalence across countries (Jowell et al. 2007). To achieve results with a very high degree of cross-country comparability, strict protocols are followed (Matsuo et al. 2009). To enhance comparability, the questionnaires have been translated with careful attention to the country context, and the same sampling plan is applied in all countries (cf. Billari et al. 2011). The data are collected through face-to-face interviews in the following countries: Austria, Belgium, Bulgaria, Switzerland, Cyprus, Germany, Denmark, Estonia, Spain, Finland, France, Great Britain, Hungary, Ireland, Latvia, the Netherlands, Norway, Poland, Portugal, Romania, Russia, Sweden, Slovenia, Slovakia, and Ukraine. The ESS samples are intended to be representative of the residential population of each nation aged 15 and older, regardless of nationality, citizenship, or legal status. Any individual who has been living in the country for at least one year could be selected as respondent. Strict guidelines are used to obtain a dataset of high methodological quality. The response rates for the third round varied between $46.0 \%$ and $73.2 \%$, with an average of $63.4 \%$. The sample sizes varied between 995 (Cyprus) and 2,916 (Germany).

In the current study, we used information on 29,035 respondents from 25 countries. Given our focus on the total number of children born to an individual during his or her lifetime, we excluded respondents who had a fair chance of having additional children. We thus included in our sample respondents aged 40 or older, because only between $1.5 \%$ and $3.0 \%$ of births are to women over age 40 (Sobotka et al. 2010). Although men may be expected to have a higher percentage of their births after reaching age 40 , the share is still likely to be relatively small. The mean age of the respondents was 59.3 ( $S D=12.4$, ranging from 40 to 101 years), and $56 \%$ were female. The characteristics of the entire sample and the key variables stratified by welfare regime are presented in Table 2.

\subsection{Measures}

Number of children. The ESS respondents were asked how many children they had ever given birth to/fathered. This variable is used as the dependent variable "total number of children."

Independent individual-level variables. The following characteristics were used as individual-level predictors: gender, birth cohort, partner status, and education. Education was measured as completed years of education. For partner status, we used a measure indicating whether respondents had ever lived with a partner for three months or longer. To allow for possible non-linear cohort effects, both cohort and cohort squared were included in the analyses.

Welfare state regime. Based on the theoretical discussion above, countries were identified as having one of six welfare regime types. 







\subsection{Analysis strategy}

Descriptive analyses were performed for the whole sample, and were broken down by welfare regime. Negative binomial multilevel regression was used to investigate the statistical effects of individual and country characteristics and their interactions (both within-level and cross-level interactions) on the average number of children born to individuals in Europe. The analyses were conducted for the entire sample, and for men and women separately. The effects were then calculated for two different cohorts: respondents born before 1945 and respondents born after 1944 . Using multilevel modelling, units at the first level (individual respondents) were treated as nested within units at the next (second) level of analysis (countries), and the dependency between observations within countries was accounted for. The analyses were conducted by using the negative binomial multi-level regression procedure of MLwin, with the maximum likelihood method to estimate variance components. The negative binomial distribution was used because it is more flexible than the Poisson distribution. Several multilevel models were estimated, beginning with an intercept only model (cf. Model 1). Such a model allowed us to examine whether there was a statistically significant amount of variation in completed fertility at the country level. This estimate is presented in the results on the random part of the model.

\section{Results}

\subsection{Descriptive results}

Table 2 presents means and standard deviations of the core variables broken down by welfare regime. Overall, across countries and cohorts and for both sexes, the average number of children was 2.01. The total number of children was higher for women than for men $(m=2.11$ versus $m=2.02)$, and for individuals born before 1945 ( $m=2.24)$ than for individuals born after $1945(m=1.97)$. This reduction in the total number of children was mainly due to changes in the behaviour of respondents with low educational levels. For instance, among women with 13 or more years of completed education, the mean family size was relatively stable ( $m=1.91$ for women born before 1945 and $m=1.90$ for women born after 1944). However, among women with 12 or fewer years of completed education, the mean total number of children dropped from 2.34 among those born before 1945 to 2.13 among those born after 1944. As we can see in Table 2, there is considerable variation across welfare regimes. The average number of children per respondent was 1.72 in the post-Soviet states, but was 2.25 in the countries with a liberal welfare 
regime type. ${ }^{2}$ Overall, the mean total number of children was clearly lowest in the post-Soviet countries and in the conservative-corporatist countries, and was clearly highest in the liberal and the Mediterranean countries.

On average, respondents had attained about 11.5 years of education. Men had completed more years of education on average than women $(m=12.0$ versus $m=11.1$ ). The number of years spent in education was lowest in Mediterranean countries, at an average of eight years. In all other countries, the average number of years spent in education was 11 or more. The average age of the respondents was just over 59, and 56\% of the respondents were women. Over $90 \%$ had been partnered at some point during their life.

\subsection{Multilevel results}

To test our hypotheses, a number of multilevel models were estimated. The results are presented in Table 3 . The clearly statistically significant variation in the constant in the intercept only model (cf. Model 1) indicates that completed fertility varied across countries.

In the second model, individual characteristics were added. Overall, women reported having higher completed fertility than men. Fertility also decreased across cohorts, with older birth cohorts having higher completed fertility than younger cohorts. Our finding that the effect of cohort squared was non-significant indicates that the drop in fertility occurred in a linear fashion. The strong positive effect of the variable "ever lived with a partner" implies that respondents who had never lived with a partner had far lower levels of completed fertility than respondents who had lived with a partner during part of their reproductive lifespan.

The most important finding in Model 2 is the negative and statistically significant effect of completed years of education $(b=-.012)$. This statistical effect implies that the total number of children born to respondents across Europe was decreasing with increasing levels of education. This finding supports our first hypothesis. After the individual-level variables were included, the variance at the country level fell by almost $10 \%$ (from 0.037 to 0.034 ); which suggests that a small portion of the country differences in the total number of children is attributable to differences in the composition of the population in terms of levels of education and partner status.

Also in Model 2, we tested the hypothesis that the negative educational gradient was stronger for women than for men by including an interaction term between

2 Given the nature of our data, it was hard to validate the information on the total number of children. We extracted information on completed fertility for the birth cohorts and the countries in our classification from the Human Fertility Database (www.humanfertililty.org), and compared the ranking of the welfare states with those in our data. There were no large discrepancies. In both instances, the highest completed fertility rate was recorded in the liberal and the southern European countries, and the lowest completed fertility rate was recorded in the post-Soviet and the conservative-corporatist countries. 


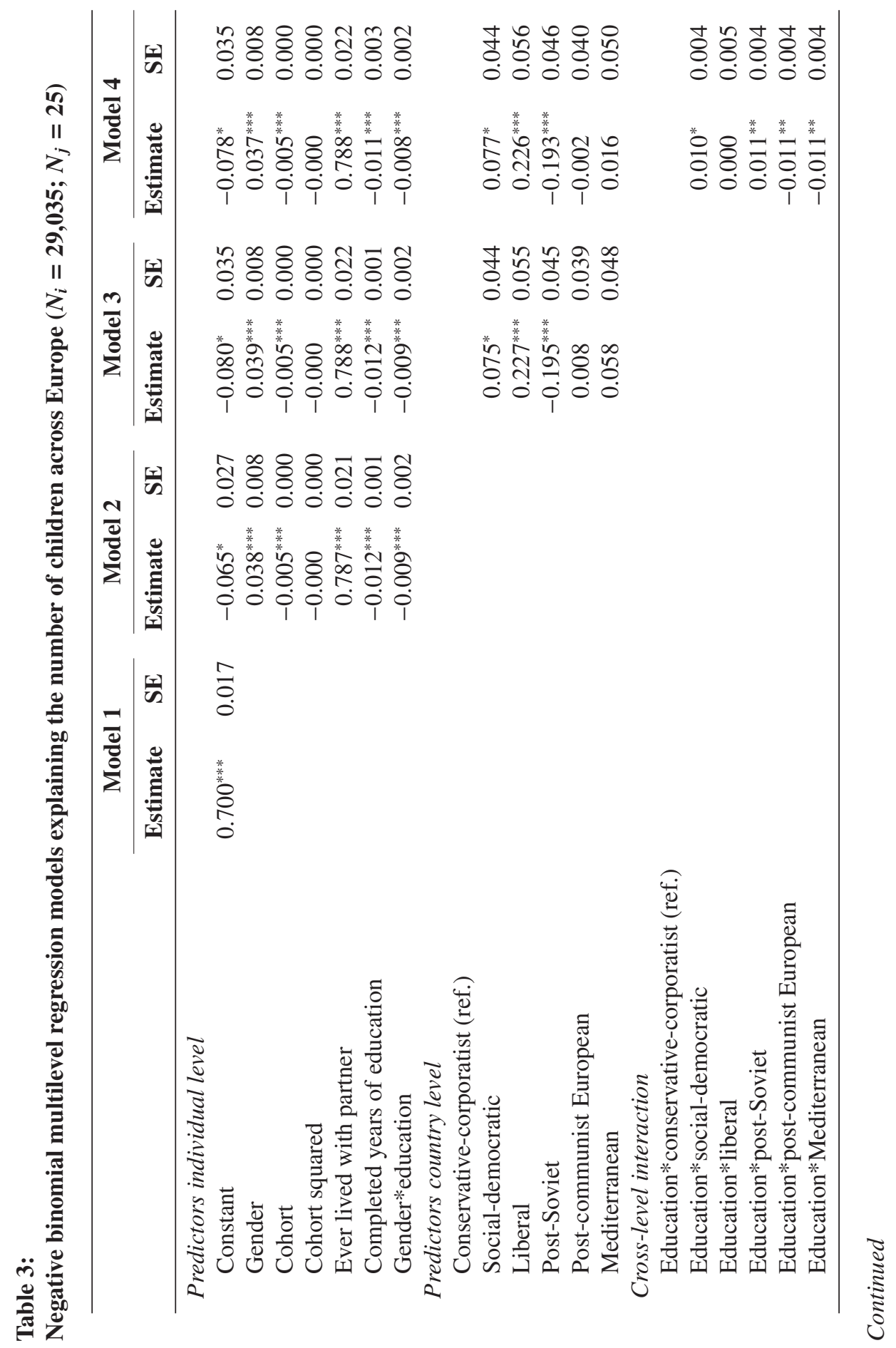




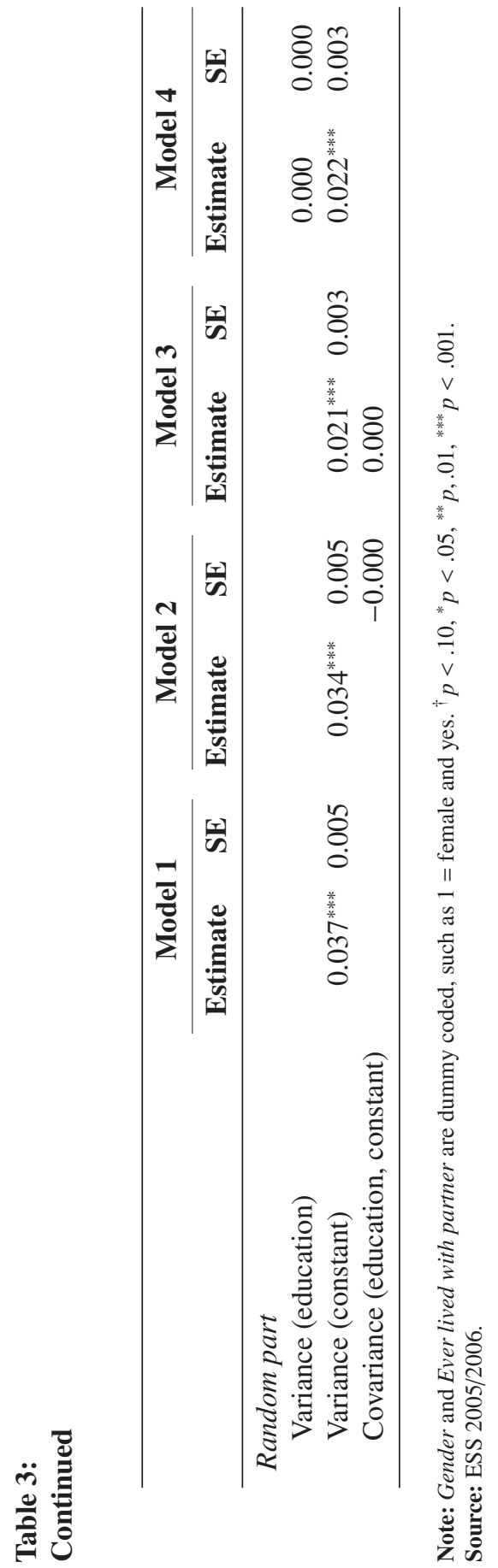


gender and education. The analysis showed that the interaction term was statistically significant and that the educational gradient in completed fertility was stronger for women $(b=-.012+-.009=-.021)$ than for men $(b=-.012)$, thereby confirming our second hypothesis. At the same time, this finding indicates that, across Europe, higher educational attainment led to lower completed family size among men as well as among women.

In Model 3, the welfare regime typology of countries was added. Countries classified as belonging to the conservative-corporatist welfare regime type constituted the reference category. Compared to these countries, the total number of children was higher in social-democratic countries $(b=.075)$ and lower in postSoviet countries $(b=-.195)$. Completed fertility was also shown to be higher in liberal countries $(b=.227)$, thereby confirming the descriptive results presented in Table 2. A surprising result of Model 3 is that the total number of children in Mediterranean countries did not differ from the total number in countries classified as conservative-corporatist. This suggests that the relatively large total number of children in Mediterranean countries shown in Table 2 was mainly attributable to the relatively low levels of educational attainment in these countries. Indeed, after educational attainment was controlled for, the differences between Mediterranean countries and the other countries in the total number of children became smaller.

Including the welfare regime typology in Model 3 decreased the country-level variance by almost $40 \%$ (from 0.034 to 0.021). Although this decrease was substantial and was statistically significant, it also indicated that there was a large degree of variation in completed fertility between countries identified as having the same welfare regime. To test whether the effect of education on the total number of children varied across welfare state regimes, a cross-level interaction between education and welfare regime was added to the model (see Model 4). The results showed that the effect of educational attainment clearly differed by welfare state regime. Among women, the negative educational gradient was found to be strongest in the Mediterranean and the post-communist European countries $(b=-.011+-.008+-.011=-.030)$, and weakest in the social-democratic and the post-Soviet countries ( $b=-.009$ and $b=-.008$, respectively). The liberal and the conservative-corporatist countries occupied a middle position $(b=-.019)$. Overall, this pattern was largely in line with expectations, with one exception: i.e. the negative educational gradient in post-Soviet countries was weaker than expected.

Up to this point, the analyses were performed jointly for men and women and for both cohorts. To get a more nuanced view of the relationship between educational attainment and the total number of children, we also performed analyses for men and women, and for cohorts born before 1945 and after 1944 separately. The results of these analyses are presented in Table 4.

The first two columns of Table 4 display the results for the cohorts born before 1945 and after 1944. The women of the older cohort had finalised their reproductive careers before 1990; i.e. at a time when eastern European countries were still under communist-led governments. In most of the western European countries outside of the Nordic countries, levels of support for combining motherhood and labour force 


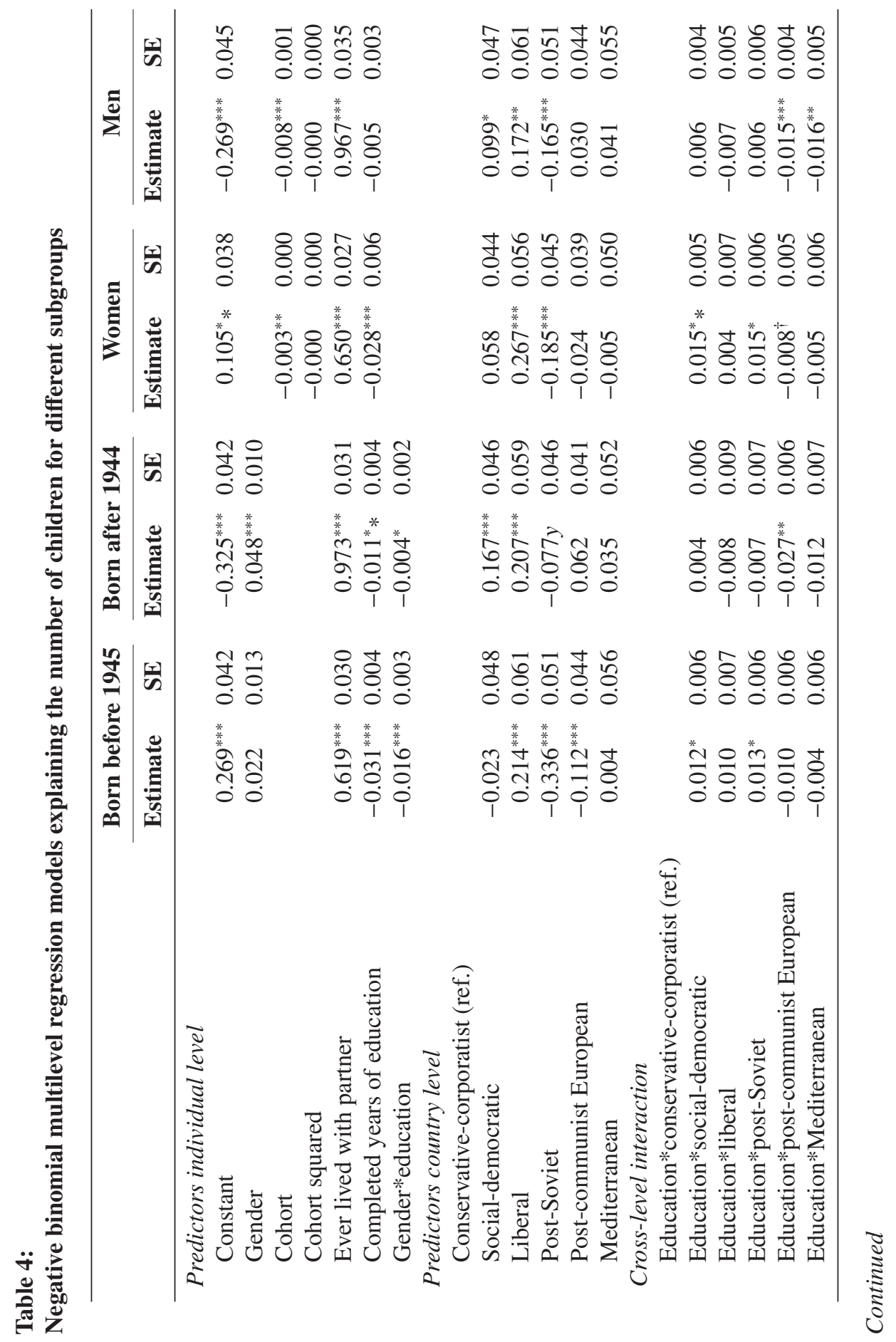




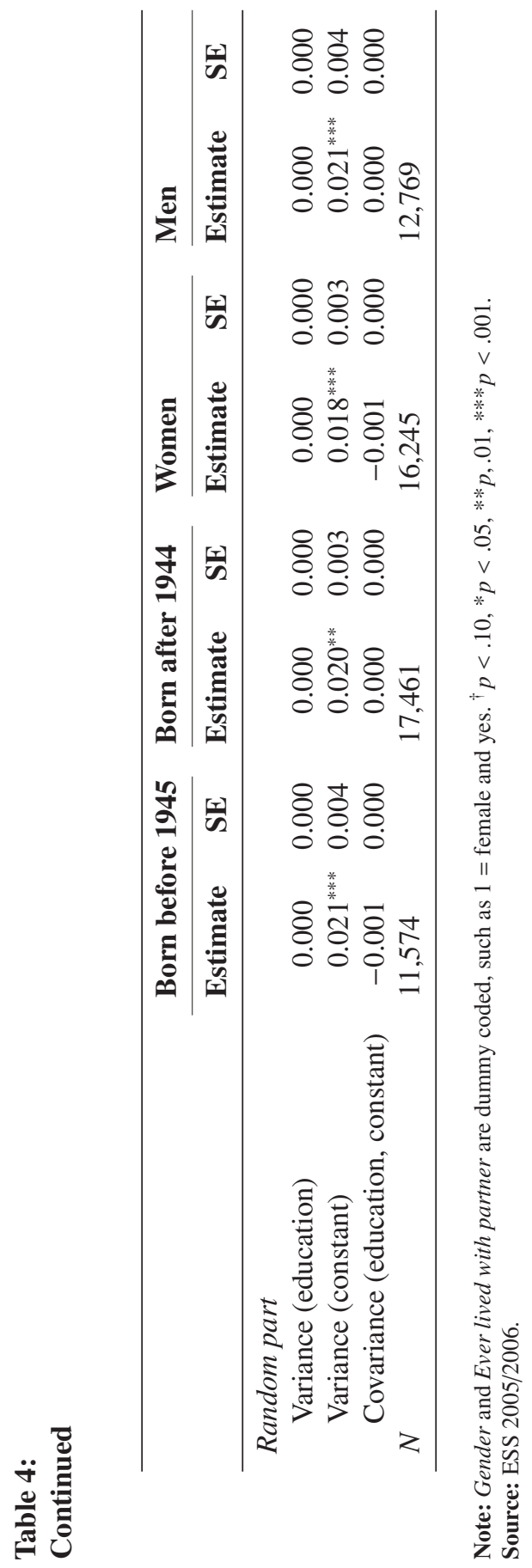


Figure 1:

Estimated educational gradient in the total number of children of women born before 1945 ("old") and women born from 1945 onwards ("young"), based on Model 4 in

Table 3

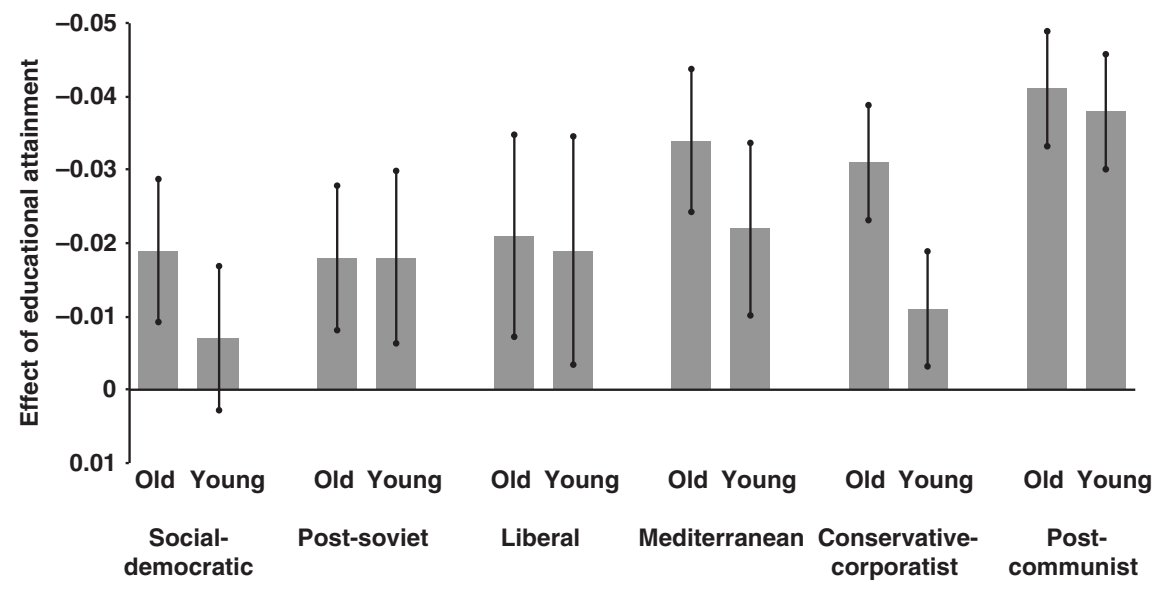

Source: ESS 2005/2006; $n_{\text {old }}=6,733 ; n_{\text {young }}=9,512$.

participation were still relatively low. The members of the younger cohort spent a portion of their reproductive careers after 1990; i.e. at a time when social structures were changing and uncertainty was increasing in eastern European countries. Many western European countries saw gradual increases in childcare services that made it easier for women to combine motherhood and labour force participation. The educational gradients for women of both cohorts in the different welfare state regimes were calculated, and the results are presented in Figure 1. ${ }^{3}$

Among women born before 1945, there was a clear negative educational gradient in all of the welfare regimes. However, this gradient was strongest in the postcommunist, the conservative-corporatist, and the Mediterranean countries. The negative gradient was weaker for the post-Soviet, the liberal, and the socialdemocratic countries. Among women born after 1944, hardly any change was observed in the countries with communist governments before 1990, which suggests that the educational gradient changed little over time (cf. Brzozowska 2014). For all of the other welfare regime types, the negative educational gradient among women was clearly weaker among women born after 1944 than before 1945 .

3 These effects are based on Models 1 and 2 in Table 4 . The easiest way to obtain these effects is by successively re-estimating Models 1 and 2 in Table 4, each time with women who were in a different welfare state category taken as the reference category. In such a model, the main effect and the standard error of "years of education" provide the effect and the standard error of educational attainment for women in the reference welfare state category. 
This weakening of the educational gradient was probably related to a decline in completed fertility across cohorts among women with low levels of education. Descriptive findings show that the average number of children decreased from 2.48 to 2.35 among women with less than nine years of education and from 2.16 to 2.05 among women with between nine and 12 years of education; and remained more or less constant (from 1.91 to 1.90) among women with $13+$ years of education.

In columns 3 and 4 of Table 4 , the results of separate analyses for men and women are presented. Across all cohorts, the negative educational gradient was clearly weaker among women in the social-democratic and the post-Soviet welfare states than in the other welfare regimes. Among men, the strongest negative educational gradients were observed in the post-communist European and the Mediterranean countries. For most of the other welfare regime types, no educational differences between men with different levels of education were observed.

Finally, given that France and Belgium introduced reconciliation policies much earlier than other countries classified as conservative welfare states, we reran the same analyses excluding France and Belgium to examine whether the positioning of the conservative welfare states was strongly influenced by the inclusion of France and Belgium in this welfare regime category. The results indicated that, generally, the differences in the educational gradients between the country groups remained the same, but the gap between the conservative welfare states on the one hand and the social-democratic and the post-Soviet countries on the other became somewhat larger, whereas the gap between the conservative welfare states and the other three types of welfare states became somewhat smaller (results available upon request from the authors). These findings suggest that the educational gradients in France and Belgium are in between those in the social-democratic and those in the corporatist-conservative group of countries.

\section{Discussion}

The aim of this study was to examine whether the educational gradient in completed family size varies across Europe. A large body of research has shown that increased educational attainment among women - and possibly among men - is associated with postponed parenthood. Less is known about whether increased educational attainment is also related to below-average levels of completed fertility.

Generally, we expected to find that an individual's ultimate number of children would be negatively related to his or her level of education. Several potential explanations for these educational differences in completed fertility have been suggested, including arguments related to autonomy, quality, and incompatibility (negative gradient); and to affordability (positive gradient). Overall, we expected to find that the first three arguments would prove more influential than the last one. Indeed, we found an overall negative educational gradient among European countries that confirmed our first hypothesis. Similar results have recently been reported elsewhere: Berrington and colleagues (2015) found for Britain a persisting 
educational gradient in fertility quantum, while Andersson and colleagues (2009) found for the Nordic countries small differences in fertility outcomes across educational groups.

The second hypothesis stated that the negative educational gradient in completed family size would be stronger among women than among men. The main reasoning behind this assertion is that incompatibility may be expected to be more relevant for women than for men. Indeed, we found that across Europe the negative educational gradient in completed family size was stronger for women than for men, which confirmed our second hypothesis. Still, the gradient was shown to be negative even for men. This result could imply a number of things. First, the autonomy and quality arguments could be of considerable importance to men as well as to women, leading highly educated men to have fewer children than less educated men. Alternatively, our findings might be attributable to educational assortative mating. If highly educated men have highly educated partners and less educated men have less educated partners, the negative gradient found among men might be explained by a failure to control for the educational effect of the female partner. To test this potential explanation, couple data on educational attainment are needed. This issue is a promising avenue for future research.

We expected to find a stronger negative relationship between the ultimate number of children and educational attainment in countries with poor arrangements for combining parenthood and employment than in countries with better arrangements. Given that the survey respondents had ended their reproductive careers at very different points in historical time, and that precise data on the institutional arrangements for combining parenthood and employment were not available for many of the countries, we opted to use a relatively crude typology to classify countries. For western European countries, we used a slightly adapted version of Esping-Andersen's (1990) welfare regime typology. For eastern European countries, we distinguished between post-Soviet states and other post-communist countries. Overall, we found limited support for our hypothesis. The negative educational gradient in completed fertility was weakest in the social-democratic (cf. Andersson et al. 2009) and the post-Soviet countries, and was strongest in the Mediterranean and the post-communist countries. For women as well as for men, it might be relatively easy to combine parenthood and labour force participation in the socialdemocratic countries, and relatively difficult in the Mediterranean countries. The relative position of the post-Soviet states is less clear. One explanation for the weak educational gradient in the post-Soviet states is that all of the educational groups in these societies were shown to have low levels of completed fertility, which suggests that work-life reconciliation was difficult to achieve for both women and men, and across educational levels. In a study for Ukraine, Perelli-Harris (2008) found that women in this country display a strong preference for having children, which has led to a pattern of early and almost universal childbearing; but that Ukrainian women are reluctant to have subsequent children. Meanwhile, the conservative welfare states of western Europe were found to have an educational gradient between these other types. Additional analyses have suggested that the educational gradients in 
France and Belgium are closer to the educational gradients in the social-democratic countries than to the educational gradients in the other conservative countries.

We further explored differences in the educational gradients across and within welfare regimes. The most interesting finding is that the negative gradient was weaker for younger than for older cohorts in western Europe, especially in the conservative-corporatist countries. This effect might have been driven by the relatively early introduction of reconciliation policies in conservative-corporatist countries such as France and Belgium. This finding partly confirms our fourth hypothesis. In countries where policies aimed at making it easier to combine family and career have been implemented in recent decades, the educational gradient has become weaker. Furthermore, the differences across western welfare regimes in the educational gradient among women and men born after 1944 were much smaller than among women and men born before 1945. The reduction in the educational gradient across cohorts seems to have been primarily caused by a decline in the total number of children born to individuals with low levels of educational attainment, while the total number of children born to individuals with tertiary education remained more or less constant across cohorts. These additional findings have several implications. First, the relatively small differences by educational level in the total number of children of the cohorts born after 1944 suggest that education could have a much stronger effect on the timing of childbearing than on the fertility quantum. While the highly educated clearly have a tendency to postpone entry into parenthood, at least in western Europe, they currently have almost as many children as the less educated. Second, one potential explanation for why hardly any reduction in completed fertility was observed for the highly educated, whereas a clear reduction was observed for the less educated, is that a diffusion process is operating. The trend towards a reduction in the number of children may have started relatively early among individuals with higher levels of education, and this process may have been finalised among the oldest cohort in our sample. Indeed, Skirbekk (2008) has suggested that this process occurred so early that individuals with higher education appear to have had fewer children throughout the 20th century. If a tendency to limit family size has been diffusing to the less educated with some time lag, a "catching-up" effect may be observed among the less educated born after 1944. Such an assumption would fit the pattern shown in Table 4 and Figure 1. However, another interpretation of this trend is also possible. Our finding that the total number of children stayed relatively stable for both cohorts of highly educated women could signal that these women were successful in striking a balance between parenthood and labour force participation. By contrast, the reduction in the total number of children born to less educated women across cohorts may signal that these women have yet to strike this balance. These trends could have cultural reasons, such as a reluctance among less educated women to outsource childcare; or they could have more structural reasons, such as that less educated women lack the resources to pay for professional childcare. More detailed data analyses are needed to test these potential explanations. A final interesting finding from our additional analyses is that the negative educational gradient in the eastern 
European countries did not change across cohorts. The negative gradient remained particularly strong for the post-communist countries, but it also held steady for the post-Soviet countries. Given that the women in the cohorts born before 1945 had completed their reproductive careers by 1990, whereas the women in the younger cohorts experienced a portion of their reproductive careers after the fall of the communist regimes, it is possible that this sharp political and economic break affected the "childbearing context" of all of the educational groups in similar ways, and thus triggered little change in the educational gradient. However, we need to acknowledge that most of our post-1944 cohorts were relatively old at the time of the transformative events of 1990 . Since women tend to have children relatively early in many eastern European countries, the collapse of communism may have had little effect on the completed fertility of the women under study.

Our results shed light on the magnitude of the negative educational gradient in completed fertility across Europe. To examine this issue, we needed micro-level data for a large number of European countries on cohorts who had completed their reproductive careers. The European Social Survey is one of the few surveys that provide such data. Still, our data and analyses suffer from a number of limitations that should be addressed in future research. First, the ESS has relatively small sample sizes. The number of respondents per country was too small to allow us to analyse the data on separate countries in a meaningful way. "Zooming in" on specific interesting countries would require larger datasets that include information on both educational attainment and the total number of children. Second, we used a relatively crude - yet theoretically grounded - typology for classifying European countries according to the degree to which they support women in combining parenthood and labour force participation. Ideally, more specific macrolevel indicators of such issues, like those available in Gauthier's Comparative Family Policy Database or the OECD Family Database, should be used. However, many of the countries covered in the ESS are not covered in these databases. For the analysis of completed fertility, there was the additional challenge of deciding which period policy indicators we would refer to in seeking to understand the policy situation during an individual's reproductive career. One solution to this problem would be to focus on the impact of educational attainment on different parities, and to try to formulate an "aggregated" conclusion. However, the data requirements for such an approach are large, and meeting them may be possible for specific countries only (e.g. Kravdal and Rindfuss 2008). Third, our indicator of educational attainment was based on the completed level at the time of the survey. This can lead to a bias in the estimates of the educational gradient (Hoem and Kreyenfeld 2006; Kravdal 2007): an overestimation of the educational effect is likely, particularly in countries with patterns of early childbearing, and where people routinely extend their educational careers into their late twenties or early thirties. Having data on educational careers might be helpful here, but such information could be used only in an approach that analyses the effect of education on one parity at a time (Wood et al. 2014). Fourth, births tend to be underreported in surveys, and this is particularly likely to be the case for men. As a result, the 
descriptive results for men are likely biased (Joyner et al. 2012). If men with high and low levels of education have similar tendencies to underreport their fertility, this underreporting would not influence the educational gradient among men. If, however, less educated men have higher numbers of early and non-marital births than highly educated men, they may also have greater tendencies to underreport their number of children. If this is the case, the educational gradient among men might be somewhat underestimated. A final limitation is that we analysed the educational gradient for men and women separately. Given that the level of educational homogamy within couples is relatively high, it is hard to disentangle the influence of the male and the female partners' educational levels (Corijn et al. 1996).

\section{Funding}

This work was supported by the European Commission within the project "Reproductive Decision-Making in a Macro-Micro Perspective" (REPRO) in the Seventh Framework Programme under the Socio-Economic Sciences and Humanities theme (Grant SSH-CT-2008-217173).

Preparation of this article has also profited from a grant by the European Science Foundation and the Dutch Science Foundation to the LIFETIMING project (Netherlands Organization for Scientific Research Grant 460-08-162).

\section{Conflict of interest}

The authors declare that they have no conflict of interest.

\section{References}

Adsera, A. 2011. Where are the babies? Labor market conditions and fertility in Europe, European Journal of Population 27(1): 1-32.

Andersson, G., L. B. Knudsen, G. Neyer, K. Teschner, M. Rønsen, T. Lappegård, K. Skrede and A. Vikat 2009. Cohort fertility patterns in the Nordic countries. Demographic Research 20: 313-352.

Becker, G. S. 1981. A treatise on the family. Cambridge: Harvard University Press.

Berrington, A., J. Stone and E. Beaujouan 2015. Educational differences in timing and quantum of childbearing in Britain: A study of cohorts born 1940-1969. Demographic Research 33: 733-764.

Billari, F. C., A. Goisis, A. C. Liefbroer, R. A. Settersten, A. Aassve, G. Hagestad, and Z. Spéder 2011. Social age deadlines for the childbearing of women and men. Human Reproduction 26: 616-622. 
Blossfeld, H. P., E. Klijzing, M. Mills and K. Kurz, eds. 2003. The losers of globalization: Becoming an adult in uncertain times. Oxford: Routledge.

Bonoli, G. 1997. Classifying welfare states: a two-dimensions approach. Journal of Social Policy 26(3): 351-372.

Brzozowska, Z. 2014. Fertility and education in Poland during state socialism. Demographic Research 31: 319-336.

Corijn, M., A. C. Liefbroer and J. De Jong Gierveld 1996. It takes two to tango, doesn't it? The influence of couple characteristics on the timing of the first birth. Journal of Marriage and the Family 58(1): 117-126.

Craig, L. 2006. Parental education, time in paid work and time with children: An Australian time-diary analysis. British Journal of Sociology 57(4): 553-575.

Ekert-Jaffe, O., and H. Stier 2009. Normative or economic behavior? Fertility and women's employment in Israel. Social Science Research 38(3): 644-655.

Engelhardt, H., T. Kögel and A. Prskawetz 2004. Fertility and women's employment reconsidered: A macro-level time-series analysis for developed countries, 1960-2000. Population Studies 58(1): 109-120.

Esping-Andersen, G. 1990. The three worlds of welfare capitalism. Cambridge: Polity Press.

Esping-Andersen, G. 1996. Welfare states without work: The impasse of labour shedding and familialism in continental European social policy. In G. Esping-Andersen (ed.), Welfare states in transition. National adaptations in global economies. London: Sage, 66-87.

Esping-Andersen, G. 2009. The incomplete revolution. Adapting to women's new roles. Cambridge: Polity Press.

Fenger, H. J. M. 2007. Welfare regimes in central and eastern Europe: Incorporating postcommunist countries in a welfare regime typology. Contemporary Issues and Ideas in Social Sciences 3(2): 1-30.

Ferrera, M. 1996. The Southern model of welfare in social Europe. Journal of European Social Policy 6(1): 17-37.

Frejka, T. 2008. Determinants of family formation and childbearing during the societal transition in Central and Eastern Europe. Demographic Research 19: 139-170.

Frejka, T., and T. Sobotka 2008. Fertility in Europe: Diverse, delayed and below replacement. Demographic Research 19: 15-46.

Giddens, A. 1991. Modernity and self-identity: Self and society in the late modern age. Cambridge: Polity Press.

Hanushek, E. A. 1992. The trade-off between child quantity and quality. The Journal of Political Economy 100(1): 84-117.

Hilgeman, C. and C. T. Butts 2009. Women's employment and fertility: A welfare regime paradox. Social Science Research 38(1): 103-117.

Hoem, J. M. and M. Kreyenfeld 2006. Anticipatory analysis and its alternatives in life-course research. Demographic Research 15: 461-484.

Joyner, K., H. E. Peters, K. Hynes, A. Sikora, J. Taber and M. Rendall 2012. The quality of male fertility data in major U.S. surveys. Demography 49(1): 101-124.

Jowell, R., C. Roberts, R. Fitzgerald and G. Eva 2007. Measuring attitudes cross-nationally: Lessons from the European Social Survey. Los Angeles: Sage. 
Kalmijn, M. and C. Saraceno 2008. A comparative perspective on intergenerational support. Responsiveness to parental needs in individualistic and familialistic countries. European Societies 10(3): 479-508.

Kalwij, A. 2010. The impact of family policy expenditure on fertility in Western Europe. Demography 47(2): 503-519.

Koropeckyj-Cox, T. and G. Pendell 2007. The gender gap in attitudes about childlessness in the United States. Journal of Marriage and Family 69(4): 899-915.

Kravdal, Ø. 2007. Effects of current education on second-and third-birth rates among Norwegian women and men born in 1964: Substantive interpretations and methodological issues. Demographic Research 17: 211-246.

Kravdal, Ø. and R. R. Rindfuss 2008. Changing relationships between education and fertility: A study of women and men born 1940 to 1964. American Sociological Review 73(5): 854-873.

Kreyenfeld, M. 2010. Uncertainties in female employment careers and the postponement of parenthood in Germany. European Sociological Review 26(3): 351-366.

Lesthaeghe, R. (1995). The Second Demographic Transition in Western countries: An interpretation. In K. O. Mason and A.-M. Jensen (eds.), Gender and Family Change in Industrialized Countries. Oxford: Clarendon Press, 17-62.

Lesthaeghe, R. and J. Surkyn 1988. Cultural dynamics and economic theories of fertility change. Population and Development Review 14(1): 1-45.

Lesthaeghe, R. and D. J. Van de Kaa 1986. Twee demografische transities? [Two demographic transitions?] In D. J. Van de Kaa and R. Lesthaeghe (eds.), Bevolking: Groei en Krimp [Polpulation: Growth and Decline]. Deventer: Van Loghum Slaterus, 9-24.

Liefbroer, A. C. and M. Corijn 1999. Who, what, where, and when? Specifying the impact of educational attainment and labour force participation on family formation. European Journal of Population 15(1): 45-75.

Luci-Greulich, A. and O. Thévenon 2013. The impact of family policies on fertility trends in developed countries. European Journal of Population 29(4): 387-416.

Matsuo, H., K. Symons, K. Beullens and J. Billiet 2009. Response based quality assessment in the ESS-Round 3: An update for 23 countries. Leuven, Belgium: K.U. Leuven Centre for Sociological Research.

Matysiak, A. and D. Vignoli 2007. Fertility and women's employment: A meta-analysis. European Journal of Population 24(4): 363-384.

McDonald, P. 2000. Gender equity in theories of fertility transition. Population and Development Review 26(3): 427-439.

Meyer, J. W. 1986. Self and the life course: Institutionalization and its effects. In A. B. Sørensen, F. E. Weinert and L. R. Sherrod (eds.), Human development and the life course: Multidisciplinary perspectives. Hillsdale: Lawrence Erlbaum, 199-216.

Mills, M. 2007. Individualization and the life course: Toward a theoretical model and empirical evidence. In C. Howard (ed.), Contested Individualization. Toronto: Palgrave McMillan, 61-79.

Muresan, C. and J. M. Hoem 2010. The negative educational gradients in Romanian fertility. Demographic Research 22(4): 95-114. 
Myrskylä, M., H. P. Kohler and F. C. Billari 2009. Advances in development reverse fertility declines. Nature, 460, 741-743.

Neels, K. and D. De Wachter 2010. Postponement and recuperation of Belgian fertility: How are they related to rising female educational attainment? Vienna Yearbook of Population Research 8: 77-106.

Perelli-Harris, B. 2008. Family formation in Post-Soviet Ukraine: Changing effects of education in a period of rapid social change. Social Forces 87(2): 767-794.

Perelli-Harris, B. and T. Gerber 2011. Nonmarital childbearing in Russia: Second Demographic Transition or Pattern of Disadvantage? Demography 48(1): 317-342.

Perelli-Harris, B., W. Sigle-Rushton, M. Kreyenfeld, T. Lappegård, R. Keizer and C. Berghammer 2010. The educational gradient of childbearing within cohabitation in Europe. Population and Development Review 36(4): 775-801.

Rondinelli, C., Aassve, A. and F. C. Billari 2010. Women's wages and childbearing decisions: Evidence from Italy. Demographic Research 22: 549-578.

Sayer, L. C., S. M. Bianchi and J. P. Robinson 2004. Are parents investing less in children? Trends in mothers' and fathers' time with children. American Journal of Sociology 110(1): $1-43$.

Skirbekk, V. 2008. Fertility trends by social status. Demographic Research 18: 145-180.

Sobotka, T. 2004. Postponement of childbearing and low fertility in Europe. Groningen: Dutch University Press.

Sobotka, T., F. C. Billari and H. P. Kohler 2010. The return of late childbearing in developed countries: Causes, trends and implications. Vienna: Vienna Institute of Demography.

Stange, K. 2011. A longitudinal analysis of the relationship between fertility timing and schooling. Demography 48(3): 931-956.

Stoop, I., J. Billiet, A. Koch and R. Fitzgerald 2010. Improving survey response: Lessons learned from the European Social Survey. Chichester, UK: Wiley.

Thévenon, O. and A. H. Gauthier 2011. Family policies in developed countries: a 'fertilitybooster' with side-effects. Community, Work E Family 14(2): 197-216.

Van Bavel, J. 2010. Choice of study discipline and the postponement of motherhood in Europe: The impact of expected earnings, gender composition, and family attitudes. Demography 47(2): 439-458.

Van de Kaa, D. J. 1987. Europe's second demographic transition. Population Bulletin 42(1): $1-57$.

Van de Kaa, D. J. 1996. Anchored narratives: The story and findings of half a century of research into the determinants of fertility. Population Studies 50(3): 389-432.

Waite, L. J., F. K. Goldscheider and C. Witsberger 1986. Nonfamily living and the erosion of traditional family orientations among young adults. American Sociological Review 51(4): 541-554.

Wood, J., K. Neels and T. Kil 2014. The educational gradient of childlessness and cohort parity progression in 14 low fertility countries. Demographic Research 31(46): 1365-1416. 